\title{
Occurrence of HHIP gene CpG island methylation in gastric cancer
}

\author{
YU SONG and YUN ZUO \\ Department of Oncology, Zhangjiagang First People's Hospital, Suzhou, Jiangsu 215600, P.R. China
}

Received January 25, 2014; Accepted August 7, 2014

DOI: $10.3892 / \mathrm{ol} .2014 .2518$

\begin{abstract}
The present study aimed to observe the methylation status of the $\mathrm{CpG}$ islands at the human hedgehog interacting protein (HHIP) gene in gastric cancer tissues, peritumoral tissues and the AGS cell line, to analyze the association between the methylation status of the $\mathrm{CpG}$ islands and the tumorigenesis of gastric cancer. The HHIP mRNA expression in 60 human gastric carcinnoma tissues, peritumoral tissues and the gastric carcinoma AGS cell line were detected by reverse transcription polymerase chain reaction (RT-PCR). The HHIP methylation status of the promoter region in the gastric carcinnoma tissues and peritumoral tissues was detected by methylation-specific PCR (MSP). Prior to and following treatment with methyl transferase inhibitor 5-aza-2'-deoxycitydine (5-aza-dc), the HHIP mRNA expression level, the methylation status of the promoter region and the methylation site loci on the $\mathrm{CpG}$ islands in the AGS cells were detected by RT-PCR, MSP and bisulfite sequencing PCR (BSP), respectively. The correlation between the methylation status of the $\mathrm{CpG}$ islands at the HHIP promoter region and the HHIP mRNA expression level were analyzed. It was found that the expression level of the HHIP mRNA in the gastric carcinoma tissues was significantly lower than that in the adjacent tissues $(0.82 \pm 0.38$ vs. $1.60 \pm 0.26$, respectively; $\mathrm{P}<0.001)$. No significant correlations were observed between the expression of HHIP mRNA and age, gender, tumor-node-metastasis stage, differentiation degree and presence of lymph node metastasis $(\mathrm{P}>0.05)$. The degree of methylation of the HHIP gene promotor in the peritumoral tissues $(17.7 \pm 3.59 \%)$ was significantly lower than that in the gastric cancer tissues $(62.9 \pm 6.14 \%)$ and in the AGS cells $(99.7 \pm 0.67 \%)(\mathrm{P}<0.05)$. Compared with prior to 5 -aza-dc intervention, the HHIP mRNA expression level in the AGS cells was significantly increased subsequent to intervention ( $0.21 \pm 0.12$ vs. $4.68 \pm 0.22$; $\mathrm{P}<0.01$ ), while the degree of methylation in the AGS cells was significantly decreased $(90.2 \pm 0.67$ vs. $10.1 \pm 0.21 \%$; $\mathrm{P}<0.01)$,
\end{abstract}

Correspondence to: Miss. Yu Song, Department of Oncology, Zhangjiagang First People's Hospital, 68 Jiyang West Road, Zhangjiagang, Suzhou, Jiangsu 215600, P.R. China

E-mail: sy5449@163.com

Key words: HHIP gene, gastric cancer, methylation and the methylation sites in $\mathrm{CpG}$ islands were significantly reduced. The degree of HHIP methylation showed a negative correlation with the level of mRNA expression ( $\mathrm{r}=-0.693$; $\mathrm{P}<0.01)$. It can be hypothesized that a high degree of methylation of the HHIP gene promoter $\mathrm{CpG}$ islands in gastric cancer tissues and cells causes a decrease in HHIP mRNA expression, which may be involved in the carcinogenesis of gastric cancer.

\section{Introduction}

Globally, gastric cancer is one of the most common cancers, the third most frequent malignancy and the second most common cause of cancer-related mortality annually $(1,2)$. Gastric cancer is usually diagnosed in the later stages of the disease and has an extremely poor prognosis, as patients have unresectable, metastatic or recurrent gastric cancer with few available therapeutic options (3). Therefore, there is an urgent requirement to extensively investigate the molecular mechanisms of gastric carcinogenesis, and to develop novel therapeutic strategies for the control of gastric cancer.

Previous studies (4-6) have found that various methylation abnormalities can lead to gene inactivation and gene silencing, promoting the development of gastric cancer. The human hedgehog interacting protein (HHIP) gene is located on chromosome 4q31.21 31.3. HHIP was identified via the screening of a mouse cDNA expression library for proteins that bind to Shh. HHIP binds all three hedgehog (Hh) proteins with an affinity equal to that of Ptc-1 and thus, functions to negatively regulate the Hh pathway. Abnormalities in the activation of the Hh signaling pathway are one cause of the occurrence and development of tumors; the HHIP gene is a negative feedback factor of this pathway, which can directly inhibit the Hh pathway, and has been shown to have a significant role in development (7-9). At present, the expression of the HHIP gene in human gastric cancer and its association with the $\mathrm{CpG}$ island methylation status of the promoter has not been reported. The present study aimed to analyze the methylation of the HHIP gene in patients with gastric carcinoma.

\section{Materials and methods}

Clinical specimens. Surgical specimens from 60 patients with gastric cancer and adjacent normal tissues were collected from the Department of Surgery, Zhangjiagang First People's Hospital (Jiangsu, China) between 2009 and 2013. All surgically 

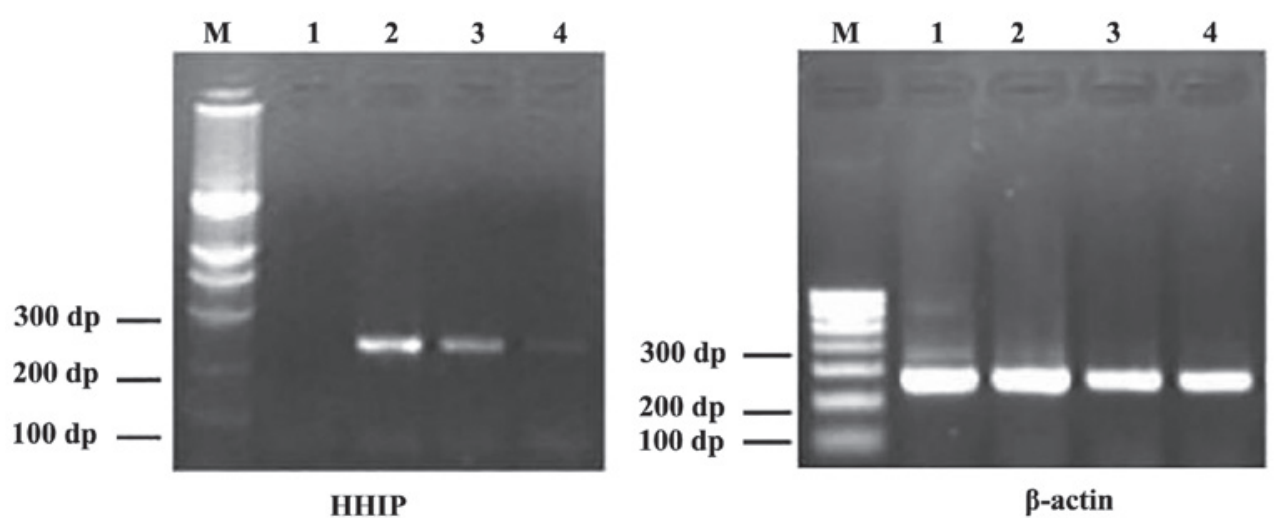

Figure 1. Expression of HHIP mRNA in gastric cancer, peritumoral tissues and gastric cancer AGS cells. M, marker; 1, AGS cells; 2 and 3, adjacent tissues; 4, gastric cancer tissues; HHIP, human hedgehog interacting protein.

resected tissue specimens were snap-frozen in liquid nitrogen until use. These specimens were examined by at least two experienced pathologists and tumor classification was made using the tumor-node-metastasis (TNM) classification. The patients consisted of 34 males and 26 females with an age range between 36 and 72 years (median, 60.82 years). According to the TNM staging system, 40 cases were stage II patients and 20 cases were stage III patients. A total of 32 tumors were well- and moderately-differentiated, while 28 were poorly-differentiated. A total of 24 tumors exhibited lymph node metastasis, whereas 36 cases were without lymph node metastasis. The study was approved by the ethics committee of Zhangjiagang First People's Hospital. Written informed consent was provided by all patients.

Cell culture and 5-aza-2'-deoxycytidine (5-aza-dc) treatment. The gastric cancer AGS cell line was purchased from the Shanghai Institute of Life Science Cell Information Center of the Chinese Academy of Sciences (Shanghai, China) and cultured in RPMI-1640 (Invitrogen, Carlsbad, CA, USA) supplemented with $10 \%$ fetal bovine serum (FBS), $100 \mu \mathrm{g} / \mathrm{ml}$ streptomycin and $100 \mathrm{U} / \mathrm{ml}$ penicillin at $37^{\circ} \mathrm{C}$ in a humidified atmosphere with $5 \% \mathrm{CO}_{2}$. Cells in the logarithmic growth phase were cultured for $\sim 24 \mathrm{~h}$ until they had reached $80 \%$ confluence, and then $5 \times 10^{6} \mathrm{~mol} / 1$ 5-Aza-dc (Sigma, St. Louis, MO, USA) was added. The liquid was changed once after $24 \mathrm{~h}$ and then the cells were harvested following $72 \mathrm{~h}$ of continuous treatment.

RNA isolation and reverse transcription polymerase chain reaction $(R T-P C R)$. Evaluate of HHIP mRNA expression using RT-PCR. Total RNA from the AGS gastric cancer cell line was isolated using TRIzol reagent (Shanghai Jingmei Bioengineering Co., Ltd., Shanghai, China) and converted into cDNA. The primer sequences of HHIP were as follows: forward, 5'-CTGCTTCTGTATTCAGGAGGTT-3' and reverse, 5'-GGGATGGAATGCGAGGCTTA-3', with an amplified fragment length of $229 \mathrm{bp}$. The primer sequences of the internal control, $\beta$-actin, were as follows: forward, 5'-AGAGCTACGAGCTGCCTGAC-3' and reverse, 5'-AGCACTGTGTTGGCGTACAG-3', with an amplified fragment length of $184 \mathrm{bp}$. The volume of the reaction agents was $20 \mu \mathrm{l}$, with reaction conditions of $95^{\circ} \mathrm{C}$ for $5 \mathrm{sec}, 55^{\circ} \mathrm{C}$ for
$5 \mathrm{sec}$ and $72^{\circ} \mathrm{C}$ for $30 \mathrm{sec}$. The PCR products were subjected to $1.5 \%$ agarose gel electrophoresis analysis.

Bisulfite conversion of DNA. Using phenol/chloroform, DNA was extracted, purified and transformed by the EZ DNA Methylation-Gold kit (Beijing Tianmo Technology Development Co., Ltd., Beijing, China).

Methylation-specific PCR (MSP) for detection of HHIP gene methylation. The HHIP MSP primer was designed by ABI Methyl Primer Express v1.0 software (Applied Biosystems, Foster City, CA, USA). The methylation primer sequences of HHIP were as follows: forward, 5'-GTAGTAGTCGGGTAGTTTCGGAATTTTC-3' and reverse, 5'-AAAAACGACTAACCGCGACG-3', with an amplified fragment length of $190 \mathrm{bp}$. The non-methylation primer sequences were as follows: forward, 5'-AGTAGTTGGGTAGTTTTGGAATTTTTGG-3' and reverse, 5'-AAAAACAACTAACCACAACA-3', with an amplified fragment length of $188 \mathrm{bp}$. The volume of the reaction agents was $50 \mu \mathrm{l}$, with reaction conditions of $94^{\circ} \mathrm{C}$ for $30 \mathrm{sec}, 60^{\circ} \mathrm{C}$ for $40 \mathrm{sec}$ and $72^{\circ} \mathrm{C}$ for $50 \mathrm{sec}$. The PCR products were subjected to $1.5 \%$ agarose gel electrophoresis analysis.

Bisulfite sequencing PCR (BSP) for detection of HHIP gene methylation sites. The HHIP BSP primer was designed by ABI Methyl Primer Express v1.0 software (Applied Biosystems). The primer sequences of HHIP were as follows: forward, 5'-GGGGAGGAGAGAGGAGTTTG-3' and reverse, 5'-CCCCACCACCTCCCTACTAC-3', with an amplified fragment length of $243 \mathrm{bp}$. The primer sequences of the internal control, $\beta$-actin, were as follows: forward, 5'-AGAGCTACGAGCTGCCTGAC-3' and reverse, 5'-AGCACTGTGTTGGCGTACAG-3', with an amplified fragment length of $184 \mathrm{bp}$. The volume of the reaction agents was $50 \mu \mathrm{l}$, with reaction conditions of $94^{\circ} \mathrm{C}$ for $30 \mathrm{sec}, 60^{\circ} \mathrm{C}$ for $40 \mathrm{sec}$ and $72^{\circ} \mathrm{C}$ for $50 \mathrm{sec}$. The BSP products were sent to Shanghai Shengong Biological Engineering Co., Ltd. (Shanghai, China) for sequence analysis.

Statistical analysis. The data was analyzed using the $\chi^{2}$ test and Student t-test, and correlation analysis was performed 
Table I. Association between HHIP mRNA and the clinical features.

\begin{tabular}{|c|c|c|c|c|}
\hline \multirow[b]{2}{*}{ Clinical features } & \multirow[b]{2}{*}{$\mathrm{n}$} & \multicolumn{3}{|c|}{ HHIP } \\
\hline & & Relative expression & $\mathrm{t}$-value & P-value \\
\hline \multicolumn{5}{|l|}{ Gender } \\
\hline Male & 34 & $1.3 \pm 0.02$ & 0.545 & 0.596 \\
\hline Female & 26 & $1.3 \pm 0.01$ & & \\
\hline \multicolumn{5}{|l|}{ Age, years } \\
\hline$<50$ & 22 & $1.3 \pm 0.02$ & 0.012 & 0.991 \\
\hline$\geq 50$ & 38 & $1.3 \pm 0.01$ & & \\
\hline \multicolumn{5}{|l|}{ TNM stage } \\
\hline II & 40 & $1.3 \pm 0.01$ & -0.031 & 0.976 \\
\hline III & 20 & $1.3 \pm 0.01$ & & \\
\hline \multicolumn{5}{|l|}{ Differentiation } \\
\hline Well and moderate & 32 & $1.3 \pm 0.02$ & 0.972 & 0.394 \\
\hline Poor & 28 & $1.3 \pm 0.01$ & & \\
\hline \multicolumn{5}{|c|}{ Lymph node metastasis } \\
\hline Yes & 24 & $1.3 \pm 0.02$ & 0.162 & 0.875 \\
\hline No & 36 & $1.3 \pm 0.01$ & & \\
\hline
\end{tabular}

HHIP, human hedgehog interacting protein; TNM, tumor-node-metastasis.
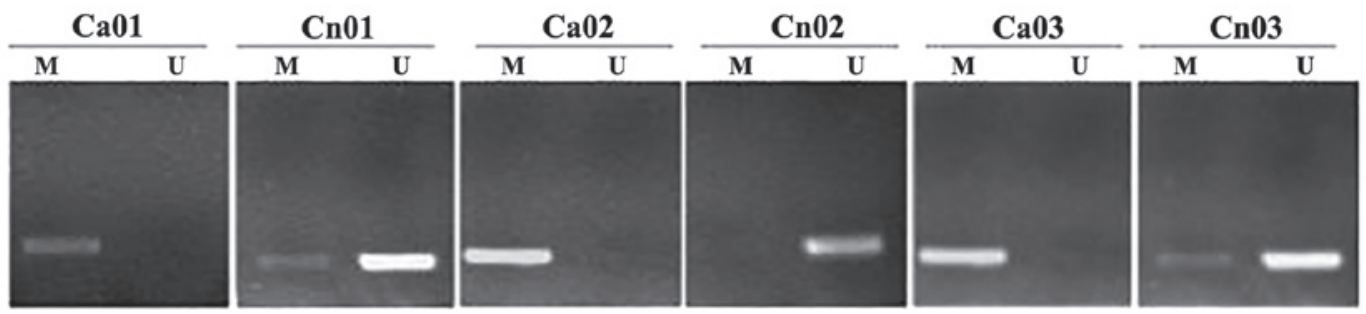

Figure 2. Detection of the methylation of human hedgehog interacting protein in gastric cancer tissues and adjacent tissues by methylation-specific polymerase chain reaction. $\mathrm{Ca}$, gastric cancer tissues; $\mathrm{Cn}$, peritumoral tissues; $\mathrm{M}$, methylated; $\mathrm{U}$, unmethylated.

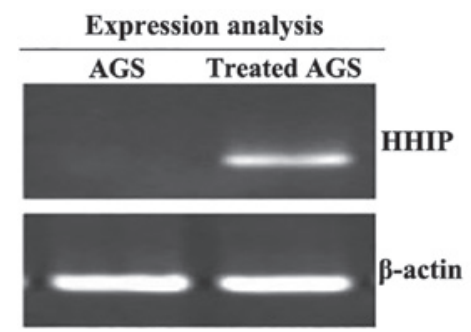

Figure 3. Expression of HHIP mRNA in gastric cancer AGS cells prior to and following 5-aza-2'-deoxycytidine treatment. HHIP, human hedgehog interacting protein.

using SPSS version 16.0 software (SPSS, Inc., Chicago, IL, USA). $\mathrm{P}<0.05$ was considered to indicate a statistically significant difference.

\section{Results}

Expression of HHIP mRNA in human gastric cancer tissues. Based on the RT-PCR results, HHIP mRNA was found to be expressed in the human gastric cancer tissues and adjacent gastric tissues, and was found to have almost no expression in the AGS cells (Fig. 1). The positive rate of HHIP mRNA expression in the gastric cancer tissues was 30\% (18/60) compared with $66.67 \%$ in the adjacent normal tissues (40/60). The relative expression in the gastric cancer tissues was lower than that in the adjacent cancer tissues $(0.8 \pm 0.38$ vs. $1.6 \pm 0.26 ; \mathrm{P}<0.001)$. No significant correlations were observed between the expression of HHIP mRNA and age, gender, TNM stage, differentiation degree and lymph node metastasis $(\mathrm{P}>0.05)$ (Table I).

Detection of HHIP gene promoter methylation in gastric cancer tissues. Based on the results of the amplification procedure performed using MSP, a number of gastric cancer tissues were shown to exhibit methylated HHIP gene promoters compared with the adjacent normal tissues, as shown in Fig. 2. No significant difference in HHIP gene promoter region methylation was observed in the gastric cancer tissues and AGS cells ( $P>0.05)$, however, the HHIP gene promoter region methylation level was significantly 
A
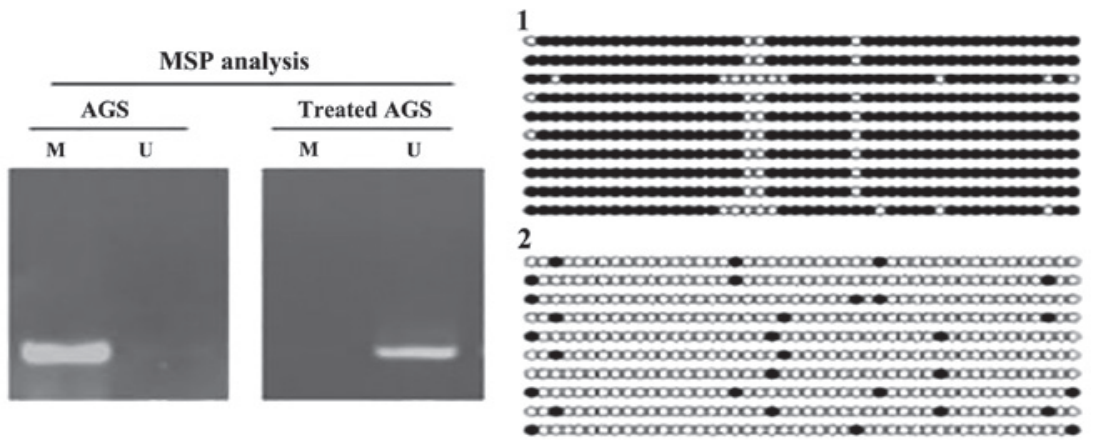

B

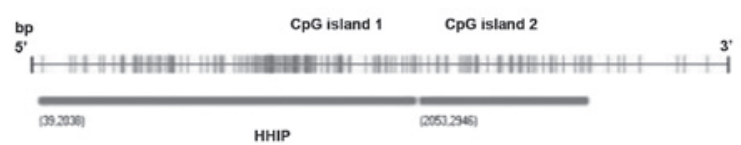

Figure 4. Differences in the methylation status of human hedgehog interacting protein in the gastric cancer AGS cell line prior to and following intervention with 5-aza-dc. 1, prior to 5-aza-dc treatment; 2, following 5-aza-dc treatment; $\mathrm{U}$ or $\mathrm{O}$, unmethylated; $\mathrm{M}$ or $\bullet$, methylated; 5-aza-dc, 5-aza-2'-deoxycytidine; MSP, methylation-specific polymerase chain reaction.(B) Software analysis of the promoter region locates two CpG islands in human hedgehog interacting protein (HHIP) mRNA.

lower in the adjacent normal tissues compared with the gastric cancer tissues and AGS cells $(17.7 \pm 3.59$ vs. $62.9 \pm 6.14$ and $99.7 \pm 0.67 \%$; all $\mathrm{P}<0.05)$.

Effects of 5-aza-dc on the expression of HHIP $m R N A$ and promoter methylation. Using RT-PCR, it was found that the AGS cells were activated following the intervention with 5-aza-dC; the expression of HHIP mRNA was significantly increased $(0.21 \pm 0.12$ vs. $4.68 \pm 0.22 ; \mathrm{P}<0.01)$ (Fig. 3). Based on the results from the amplification procedure using MSP, the methylation level was shown to be significantly decreased following 5-aza-dC treatment $(90.2 \pm 0.67$ vs. $10.1 \pm 0.21 \%$; $\mathrm{P}<0.01$ ), as shown in Fig. 3. Spearman's correlation analysis showed that HHIP gene promoter methylation was negatively correlated with mRNA expression $(r=-0.693 ; \mathrm{P}<0.001)$. With regard to the detection of the methylation status in the promoter region by the BSP method, the level of methylation significantly decreased following treatment, as shown in Fig. 4. Using $\mathrm{CpG}$ analysis (ABI Methyl Primer Express v1.0 software), the HHIP promoter region was determined to have $2 \mathrm{CpG}$ islands; the first island is located from $+39 \mathrm{bp}$ to $+2038 \mathrm{bp}$, the second island is located from +2053 to +2946 bp (Fig. 4B) The first island was used to design the HHIP primer sequence. It was found that the number of HHIP gene promoter $\mathrm{CpG}$ island methylation loci was significantly reduced following 5-aza-dC treatment.

\section{Discussion}

Methylation of tumor suppressor genes has been found to cause numerous cancers and has been a focus of tumor research in recent years. DNA methylation is a form of chemical modification, which changes genetic expression without altering the DNA sequence. In a variety of human tumor genes, the DNA methylation level is low and a degree of regional hypermethylation coexists. Previous studies (10-12) have shown that 5'-CpG island hypermethylation leads to partial inactivation of tumor suppressor genes, which is a significant cause of the malignant transformation of cells. As a result treatment with demethylation drugs, the gene expresses a tumor suppressor function. It has been found that when using 5-azacytidine to act on promoter hypermethylation, the corresponding mRNA and protein expression can be restored in the tumor cells; this confirmed the fact that promoter methylation is the main cause of the inhibition of gene expression (13-15). One study has even proposed the establishment of a pattern of DNA methylation for multiple tumor-associated genes, to facilitate the diagnosis and differential diagnosis of early (16).

The HH signaling pathway is a vital signal transduction pathway that aids in regulating embryonic development. HHIP was first identified by screening a mouse cDNA expression library for proteins that bind to sonic hedgehog (Shh). HHIP binds all three $\mathrm{Hh}$ proteins with an affinity equal to that of Ptc-1, and functions to negatively regulate the $\mathrm{Hh}$ pathway. The expression of the HHIP gene, a negative regulator of Hh signaling, has been shown to be reduced in gastric cancer tissues, but retained in normal gastric tissues or atypical hyperplasia (17-19). The present study also found that the expression of HHIP mRNA in the gastric cancer tissues was significantly lower than that in the adjacent normal tissues $(\mathrm{P}<0.05)$, supporting the aforementioned results.

Accumulating evidence has shown that DNA methylation is closely associated with gastric cancer. Studies have found that hypermethylation exists in each stage of gastric cancer, even at the precancerous lesion stage. Lee et al (20) found that the p16 gene methylation level had positive correlation with gastric carcinogenesis. The level of p16 methylation may increase in intestinal metaplasioa, chronic gastritis, polypoid adenoma and adenocarcinoma. Berman et al (21) reported that, in $2003,81 \%$ of digestive tract cancer cells, including esophageal, gastric, biliary and pancreatic cancerderived cell lines, exhibit the expression of $\mathrm{SHH}$ and its receptor, PTCH. A study by Shahi et al (22) found that HHIP hypermethylated in pancreatic cancer cell lines. These data suggest that the Hh pathway is involved in the occurrence 
and development of gastric cancer. There is currently a lack of studies with regard to HHIP gene defects and mutations in gastric cancer. The number of studies analyzing HHIP gene methylation is even less.

This study analyzed the occurrence of HHIP gene $\mathrm{CpG}$ island methylation in gastric cancer. The study found that the level of HHIP gene promoter methylation in peritumoral tissues $(17.7 \pm 3.59 \%)$ was significantly lower than that in gastric cancer tissues $(62.9 \pm 6.14 \%)$ and AGS cells $(99.7 \pm 0.67 \%)(\mathrm{P}<0.05)$. The level of HHIP methylation increased significantly in normal gastric mucosa, gastric cancer and gastric cancer cell lines. Following intervention with 5-aza-dc, the methylation level of the AGS cell line decreased significantly and non-methylation of the HHIP promoter region was observed. The $\mathrm{CpG}$ methylation status was significantly reduced, whereas the HHIP gene was activated and the mRNA expression was significantly increased. Analysis showed that the mRNA expression level was negatively correlated with the methylation level. Therefore, HHIP gene $\mathrm{CpG}$ island hypermethylation may decrease the expression of HHIP, which maybe participate in the carcinogenesis of gastric cancer, therefore methylation in HHIP gene CpG islands may be a good detection index for gastric cancer.

In conclusion, $\mathrm{HHIP}$ gene promoter $\mathrm{CpG}$ island methylation may be associated with the carcinogenesis of gastric cancer, so the detection of the HHIP gene methylation level may be a novel clinical marker for the early diagnosis of gastric cancer. HHIP and the specific mechanism of gastric cancer require further study.

\section{References}

1. de Martel C, Forman D and Plummer M: Gastric cancer: epidemiology and risk factors. Gastroenterol Clin North Am 42: 219-240, 2013.

2. Fock KM: Review article: the epidemiology and prevention of gastric cancer. Aliment Pharmacol There 40: 250-260, 2014.

3. Bollschweiler E, Berlth F, Baltin C, et al: Treatment of early gastric cancer in the Western World. World J Gastroenterol 20: 5672-5678, 2014.

4. Sheikh A, Alvi AA, Aslam HM and Haseeb A: Hedgehog pathway inhibitors - current status and future propects. Infect Agent Cancer 7: 29, 2012.

5. Gerardo Valadez J, Grover VK, Carter MD, et al: Identification of Hedgehog pathway responsive glioblastomas by isocitrate dehydrogenase mutation. Cancer Lett 328: 297-306, 2013.
6. Yun JI, Kim HR, Park H, et al: Small molecule inhibitors of the hedgehog signaling pathway for the treatment of cancer. Arch Pharm Res 35: 1317-1333, 2012.

7. Queiroz KC, Spek CA and Peppelenbosch MP: Targeting Hedgehog signaling and understanding refractory response to treatment with Hedgehog pathway inhibitors. Drug Resist Updat 15: 211-222, 2012.

8. Cobourne MT and Green JB: Hedgehog signaling in development of the secondary palate. Front Oral Biol 16: 52-59, 2012.

9. Büller NV, Rosekrans SL, Westerlund J, et al: Hedgehog signaling and maintenance of homeostasis in intestinal epithelium. Physiology (Bethesda) 27: 148-155, 2012.

10. Viatte S, Plant D and Raychaudhuri S: Genetics and epigenetics of rheumatoid arthritis. Nat Rev Rheumatol 9: 141-153, 2013.

11. Eising E, A Datson N, van den Maagdenberg AM and Ferrari MD: Epigenetic mechanisms in migraine: a promising avenue. BMC Med 11: 26, 2013.

12. Hodes GE: Sex, stress, and epigenetics: regulation of behavior in animal models of mood disorders. Biol Sex Differ 4: 1, 2013.

13. Toraño EG, Petrus S, Fernandez AF and Fraga MF: Global DNA hypomethylation in cancer: review of validated and clinical significance. Clin Chem Lab Med 50: 1733-1742, 2012.

14. Savio AJ, Lemire M, Mrkonjic M, et al: MLH1 region polymorphisms show a significant association with $\mathrm{CpG}$ island shore methylation in a large cohort of healthy individuals. PLoS One 7: e51531, 2012

15. Kim JG, Takeshima H, Niwa T, et al: Comprehensive DNA methylation and extensive mutation analyses reveal an association between the $\mathrm{CpG}$ island methylator phenotype and oncogenic mutations in gastric cancers. Cancer Lett 330: 33-40, 2013.

16. Anastasiadou C, Malousi A, Maglaveras N and Kouidou S: Human epigenome data reveal increased $\mathrm{CpG}$ methylation in alternatively spliced sites and putative exonic splicing enhancers. DNA Cell Biol 30: 267-275, 2011.

17. Lu JT, Zhao WD, He W and Wei W: Hedgehog signaling pathway mediates invasion and metastasis of hepatocellular carcinoma via ERK pathway. Acta Pharmacol Sin 33: 691-700, 2012.

18. Yun JI, Kim HR, Park H, et al: Small molecule inhibitors of the hedgehog signaling pathway for the treatment of cancer. Arch Pharm Res 35: 1317-1333, 2012.

19. Pan JY and Zhou SH: The hedgehog signaling, a new therapeutic target for treatment of ischemic heart disease. Pharmazie 67: 475-481, 2012.

20. Lee JH, Park SJ, Abraham SC, et al: Frequent CpG island methylation in precursor lesions and early gastric adenocarcinomas. Oncogene 23: 4646-4654, 2004.

21. Berman A, Mezey M, Kobayashi M, et al : Gerontological nursing content in baccalaureate nursing programs: comparison of findings from 1997 and 2003. J Prof Nurs 21: 268-275, 2005.

22. Shahi MH, Lorente A and Castresana JS: Hedgehog signalling in medulloblas toma, glioblastoma and neuroblastoma. Oncol Rep 19: 681-688, 2008. 